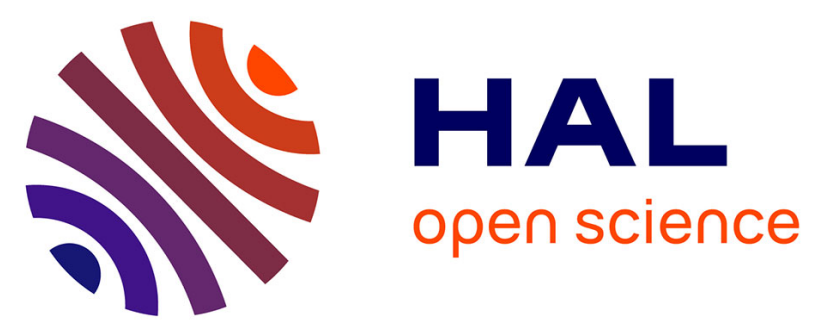

\title{
Qualitative electrochemical impedance spectroscopy study of ion transport into sub-nanometer carbon pores in electrochemical double layer capacitor electrodes
} Julie Segalini, Barbara Daffos, Pierre-Louis Taberna, Yury Gogotsi, Patrice Simon

\section{To cite this version:}

Julie Segalini, Barbara Daffos, Pierre-Louis Taberna, Yury Gogotsi, Patrice Simon. Qualitative electrochemical impedance spectroscopy study of ion transport into sub-nanometer carbon pores in electrochemical double layer capacitor electrodes. Electrochimica Acta, 2010, vol. 55, pp. 7489-7494. 10.1016/j.electacta.2010.01.003 . hal-00862100

\section{HAL Id: hal-00862100 https://hal.science/hal-00862100}

Submitted on 16 Sep 2013

HAL is a multi-disciplinary open access archive for the deposit and dissemination of scientific research documents, whether they are published or not. The documents may come from teaching and research institutions in France or abroad, or from public or private research centers.
L'archive ouverte pluridisciplinaire HAL, est destinée au dépôt et à la diffusion de documents scientifiques de niveau recherche, publiés ou non, émanant des établissements d'enseignement et de recherche français ou étrangers, des laboratoires publics ou privés. 


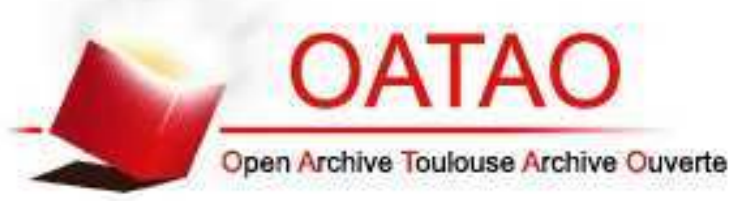

\section{Open Archive TOULOUSE Archive Ouverte (OATAO)}

OATAO is an open access repository that collects the work of Toulouse researchers and makes it freely available over the web where possible.

This is an author-deposited version published in : http://oatao.univ-toulouse.fr/ Eprints ID : 8672

To link to this article : DOI:10.1016/j.electacta.2010.01.003

URL : http://dx.doi.org/10.1016/j.electacta.2010.01.003

To cite this version : Segalini, Julie and Daffos, Barbara and Taberna, Pierre-Louis and Gogotsi, Yury and Simon, Patrice. Qualitative electrochemical impedance spectroscopy study of ion transport into sub-nanometer carbon pores in electrochemical double layer capacitor electrodes. (2010). Electrochimica Acta, vol. 55 (n²5). pp. 74897494. ISSN 0013-4686

Any correspondance concerning this service should be sent to the repository administrator: staff-oatao@ listes-diff.inp-toulouse.fr 


\title{
Qualitative Electrochemical Impedance Spectroscopy study of ion transport into sub-nanometer carbon pores in Electrochemical Double Layer Capacitor electrodes
}

\author{
J. Segalini ${ }^{a}$, B. Daffos ${ }^{\text {a }}$, P.L. Taberna ${ }^{a}$, Y. Gogotsi ${ }^{b, 1}$, P. Simon ${ }^{\mathrm{a}, *, 1}$ \\ a Université de Toulouse, CIRIMAT, UMR-CNRS 5085, 31062 Toulouse Cedex 4, France \\ ${ }^{\mathrm{b}}$ Department of Materials Science and Engineering and A.J. Drexel Nanotechnology Institute, Drexel University, Philadelphia, PA 19104, USA
}

Keywords:

Double layer capacitance

Electrochemical Impedance Spectroscopy

Ion transport

Sub-nanometer pores

Sieving effect

\begin{abstract}
A B S T R A C T
Ion adsorption onto high surface area microporous Carbide Derived Carbons (CDCs) with pore sizes in the sub-nanometer range was studied by means of the Electrochemical Impedance Spectroscopy (EIS) technique in two electrolytes, Tetraethylammonium Tetrafluoroborate $\left(\mathrm{NEt}_{4} \mathrm{BF}_{4}\right)$ in Acetonitrile (AN) and in Propylene Carbonate (PC). Polarization at two bias voltages $(0.5 \mathrm{~V} /$ Ref and $-1 \mathrm{~V} / \mathrm{Ref})$ for EIS measurements enabled comparing the capacitive behaviors resulting from anions and cations adsorption, respectively, it was confirmed that the effective size of $\mathrm{NEt}_{4}{ }^{+}$is bigger than the one of $\mathrm{BF}_{4}{ }^{-}$. Higher transport limitation was then observed for cations and was exalted in PC-based electrolyte. Although slow ion transport kinetics, it was found that the low frequency vertical line observed on the Nyquist plots was preserved meaning that carbon electrodes were fully charged. This study confirmed the importance of choosing an electrode carbon pore size adapted to the effective ion size. Finally, the best performances would be got in $1.5 \mathrm{M} \mathrm{NEt}_{4} \mathrm{BF}_{4} \mathrm{AN}$-based electrolyte with a $0.76 \mathrm{~nm}$ pore size negative electrode and a $0.68 \mathrm{~nm}$ pore size positive electrode.
\end{abstract}

\section{Introduction}

Supercapacitors, also known as Electrochemical Double Layer Capacitors (EDLC), are electrical storage systems. They are currently catching attention being an intermediate between batteries - high energy density devices - and dielectric capacitors high power density systems [1,2]. EDLCs are very powerful devices as compared to batteries, they can charge and discharge within few seconds and this for hundred thousands of cycles $(500,000)[2]$. However, they store about 20 times less energy than batteries $(150 \mathrm{Wh} / \mathrm{kg}$ for Libatteries). Depending on the power and autonomy required by the applications, EDLCs can be used as a stand-alone electrical storage device or combined with batteries when a compromise between energy and power is needed.

Today, one of the challenges is to increase the energy density of supercapacitors [1]. Using Carbide Derived Carbons (CDCs), recent results have shown that, defying conventional wisdom, micropores were accessible to the ions of the electrolyte, leading to an anomalous capacitance increase [3]. CDCs are obtained from

\footnotetext{
* Corresponding author.

E-mail address: simon@chimie.ups-tlse.fr (P. Simon).

1 ECS active member.
}

chlorination of titanium carbide (TiC) at a fixed temperature [4] offering the unique advantage of presenting tunable and narrow pore size distributions as compared to standard activated carbons. The proposed hypothesis that we put forward to explain this sharp capacitance increase previously observed by several authors $[3,5,6]$ is the distortion of the ions solvation sphere shell, which thus enables the ions to access these pores smaller than the size of the solvated ions [7-9]. Finally, experiments in solvent-free electrolytes - ionic liquids - revealed that a maximum in capacitance was achieved for carbon pore size close to the ion size [10], the Helmöltz electrochemical double layer theory falls short to describe charge adsorption in sub-nanometer pores $[10,11]$.

Finally, using the Cavity Micro-Electrode (CME), we recently confirmed the sieving effect previously reported by several groups $[5,6,8,9,12-14]$ and highlighted the solvent influence on the ion adsorption in the carbon pores, thus demonstrating that ions must be partially desolvated to enter sub-nanometer pores [7].

This paper aims to complete previous studies by understanding how ion size versus carbon pore size relationship affects ion transportation and adsorption into confined sub-nanometer pores of Carbide Derived Carbons. Electrochemical Impedance Spectroscopy (EIS) technique in two different organic electrolytes was used in order to be able to discriminate phenomena involved upon charge storage in such sub-nanometer pores. 


\section{Experimental}

Carbide Derived Carbons powders (CDCs) were obtained from TiC powders (Alfa Aesar \#40178, particle size $2 \mu \mathrm{m}$ ) which were chlorinated for $3 \mathrm{~h}$ at 500,700 and $900^{\circ} \mathrm{C}$ in a horizontal tube furnace. During this process, the Ti atoms are extracted from the substrate and create $\mathrm{TiCl}_{4}$, hence realizing pores in the carbon structure. The details of the chlorination process have been described elsewhere $[3,15]$. The chlorination was followed by annealing process for $2 \mathrm{~h}$ in hydrogen (Air Products, UN1049) at $600^{\circ} \mathrm{C}$ for removing residual chlorines and chlorides which could be trapped in the pores [16].

Argon sorption was conducted from relative pressure, $P / P_{0}$, of $10^{-6}$ to 1 to assess porosity and surface area data. Porosity analysis was carried out at liquid nitrogen temperature, $-195.8^{\circ} \mathrm{C}$, on samples outgassed for at least $12 \mathrm{~h}$ at $300^{\circ} \mathrm{C}$ using a Quantachrome Autosorb-1. Pore size distributions were calculated from Argon adsorption isotherms taken from a pressure range of $3 \times 10^{-4}$ to 205 Torr using the non-local density functional theory (NLDFT) method provided by Quantachrome data reduction software version 1.27 assuming slit pore shape and the SSA was calculated using the Brunauer, Emmett, Teller (BET) method [17].

Cyclic Voltammetry and Electrochemical Impedance Spectroscopy measurements were carried out by means of the Cavity Micro-Electrode $[12,18,19]$. A CME is made of a glass tube containing a Pt wire, etched by dissolution in aqua regia at one end to create a micro-cavity of $\sim 10^{-6} \mathrm{~cm}^{3}$ with a diameter of $150 \mu \mathrm{m}$ and a depth of $100 \mu \mathrm{m}$. A rolled platinum foil of $1 \mathrm{~cm}^{2}$ was used as counter electrode and a silver rod employed as quasi-reference electrode. The electrochemical cell was assembled in a glove box under argon atmosphere $(\mathrm{Ar} 6.0)$ to prevent any oxygen and water contaminations.

The electrochemical study was investigated in two different electrolytes: $1.5 \mathrm{M}$ Tetraethylammonium Tetrafluoroborate $\left(\mathrm{NEt}_{4} \mathrm{BF}_{4}\right.$ ) (Acros Organics, CAS \#429-06-1) in Acetonitrile (AN) (Acros Organics, CAS \#75-05-8, $\mathrm{H}_{2} \mathrm{O}<10 \mathrm{ppm}$ ) and $1 \mathrm{M} \mathrm{NEt}_{4} \mathrm{BF}_{4}$ (Acros Organics, CAS \#429-06-1) in Propylene Carbonate (PC) (Acros Organics, CAS \#108-32-7). Cyclic Voltammetry (CV) experiments were done at $100 \mathrm{mV} / \mathrm{s}$ using a multi-channel potentiostat/galvanostat (VMP3, Biologic). EIS measurements were achieved by applying a low sinusoidal amplitude alternative voltage of $20 \mathrm{mV}$ to the system at frequencies from $200 \mathrm{kHz}$ to $10 \mathrm{mHz}$ using the same apparatus as Cyclic Voltammetry. Measurements were performed at fixed voltage of $0.5 \mathrm{~V}$ and then $-1.0 \mathrm{~V}$, after reaching the steady-state current value.

\section{Results and discussion}

Figs. 1 and 2 show the Cyclic Voltammetry curves of the CDC samples measured both in $1.5 \mathrm{M} \mathrm{NEt}_{4} \mathrm{BF}_{4} \mathrm{AN}$-based electrolyte and $1 \mathrm{M} \mathrm{NEt}_{4} \mathrm{BF}_{4} \mathrm{PC}$-based electrolyte. These plots were normalized to a constant capacitive current at $0.5 \mathrm{~V} /$ Ref where $\mathrm{d} I / \mathrm{d} E$ is close to zero. The distortion of the $\mathrm{CV}$ plots from the ideal rectangular capacitive behavior, which is a consequence of the ion sieving effect observed with the smallest pore sizes, has been discussed in a previous paper and will not be detailed here [12].

EIS measurements were carried out from $200 \mathrm{kHz}$ down to $10 \mathrm{mHz}$ in the two different electrolytes, namely $1.5 \mathrm{M} \mathrm{NEt}_{4} \mathrm{BF}_{4}$ in $\mathrm{AN}$ (Fig. 3) and $1 \mathrm{M} \mathrm{NEt}_{4} \mathrm{BF}_{4}$ in PC (Fig. 4). In a first step, CDC samples were polarized from the Open Circuit Voltage (OCV) to the desired potential $(0.5$ or $-1 \mathrm{~V} / \mathrm{Ref})$ and the potential was kept constant until the current variation drops close to zero. The Nyquist plots were then recorded at a constant potential, $0.5 \mathrm{~V} /$ Ref (Figs. 3a and $4 \mathrm{a}$ ) or $-1 \mathrm{~V} / \operatorname{Ref}$ (Figs. $3 \mathrm{~b}$ and $4 \mathrm{~b}$ ), for each electrolyte tested. EIS Nyquist plots were normalized according to the value of the

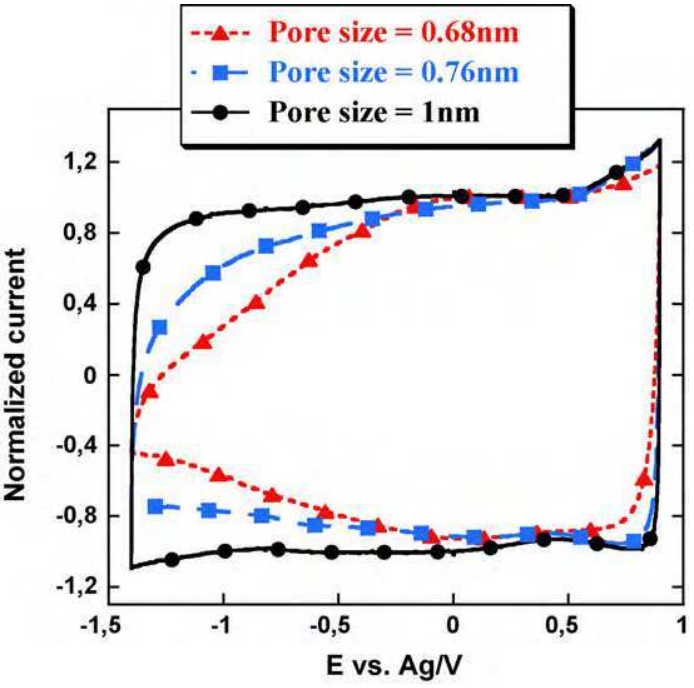

Fig. 1. Normalized CVs of the three CDC samples in $\mathrm{AN}+1.5 \mathrm{M} \mathrm{NEt}_{4} \mathrm{BF}_{4}$ electrolyte between $-1.4 \mathrm{~V} /$ Ref and $0.9 \mathrm{~V} /$ Ref. Scan rate: $100 \mathrm{mV} / \mathrm{s}$.

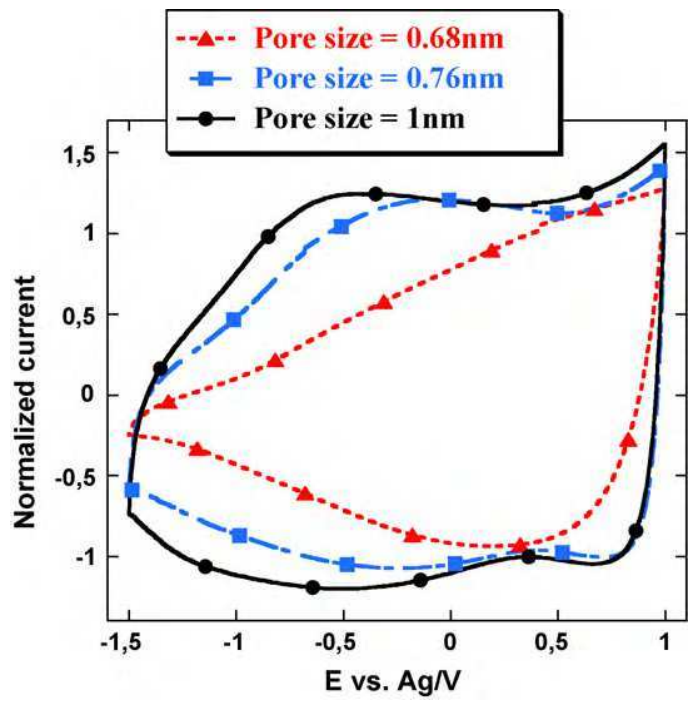

Fig. 2. Normalized CVs of the three CDC samples in $\mathrm{PC}+1 \mathrm{M} \mathrm{NEt}_{4} \mathrm{BF}_{4}$ electrolyte between $-1.5 \mathrm{~V} / \mathrm{Ref}$ and $1.0 \mathrm{~V} /$ Ref. Scan rate: $100 \mathrm{mV} / \mathrm{s}$.

real part at high frequency linked to the bulk electrolyte resistance.

\subsection{Electrochemical Impedance Spectroscopy in $1.5 \mathrm{M} \mathrm{NEt}_{4} \mathrm{BF}_{4}$ in AN electrolyte}

Fig. 3a and $b$ show the Nyquist plots of the various CDC samples in $1.5 \mathrm{M} \mathrm{NEt}_{4} \mathrm{BF}_{4}$ in $\mathrm{AN}$ at $0.5 \mathrm{~V} /$ Ref and $-1 \mathrm{~V} /$ Ref, respectively. From these experimental records, it can be seen that the plots shape strongly depends on the bias potential as well as on the nanoporous CDC pore size. The OCV was found to be about $0.2 \mathrm{~V} / \mathrm{Ref}$ for all the samples. At $0.5 \mathrm{~V} /$ Ref (Fig. 3a), the CME filled with the CDC powder is thus positively polarized and accordingly, at this potential, $\mathrm{BF}_{4}{ }^{-}$ anions are adsorbed in the carbon pores. The Nyquist plots of the three CDC samples show a similar shape whatever the pore size (see Fig. 3a), characteristic of the capacitive behavior of a porous electrode [20-23]. At high frequency $(>1 \mathrm{kHz})$, where the plots intercept the real axis, the supercapacitor behaves like a pure resistance. Between the intercept of the plot with the real axis at high frequency and the low frequency domain characterized by the sharp 

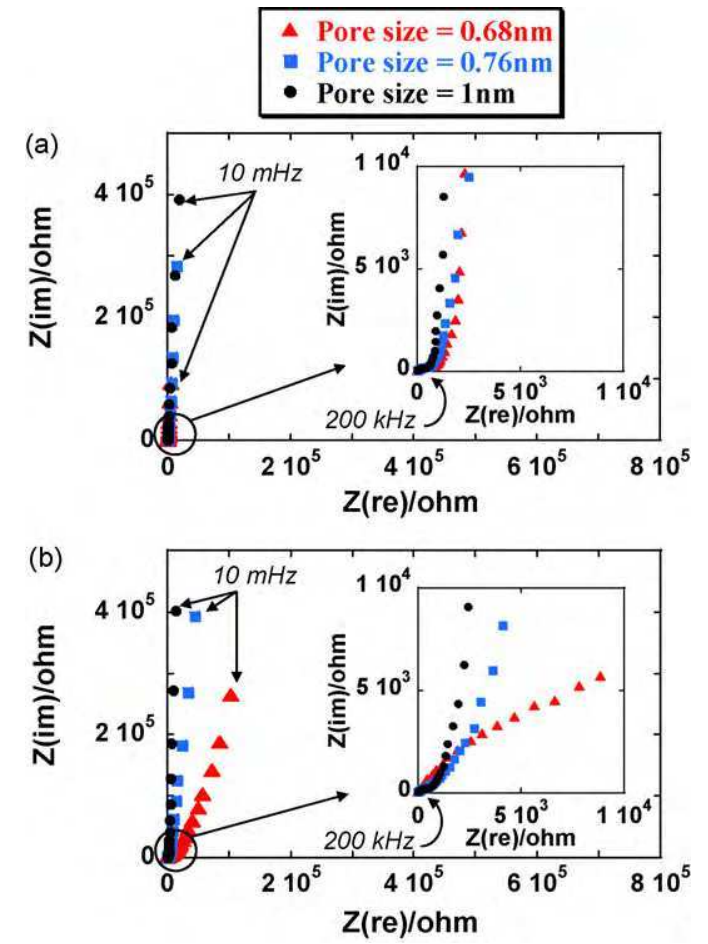

Fig. 3. (a) and (b) Nyquist plots of the three CDC samples in $\mathrm{AN}+1.5 \mathrm{M} \mathrm{NEt}_{4} \mathrm{BF}_{4}$ electrolyte at applied voltage of $0.5 \mathrm{~V} / \operatorname{Ref}(\mathrm{a})$ and $-1.0 \mathrm{~V} / \operatorname{Ref}(\mathrm{b})$ which concerns the anions and cations adsorption, respectively. A zoom at high frequencies are shown in the insets.
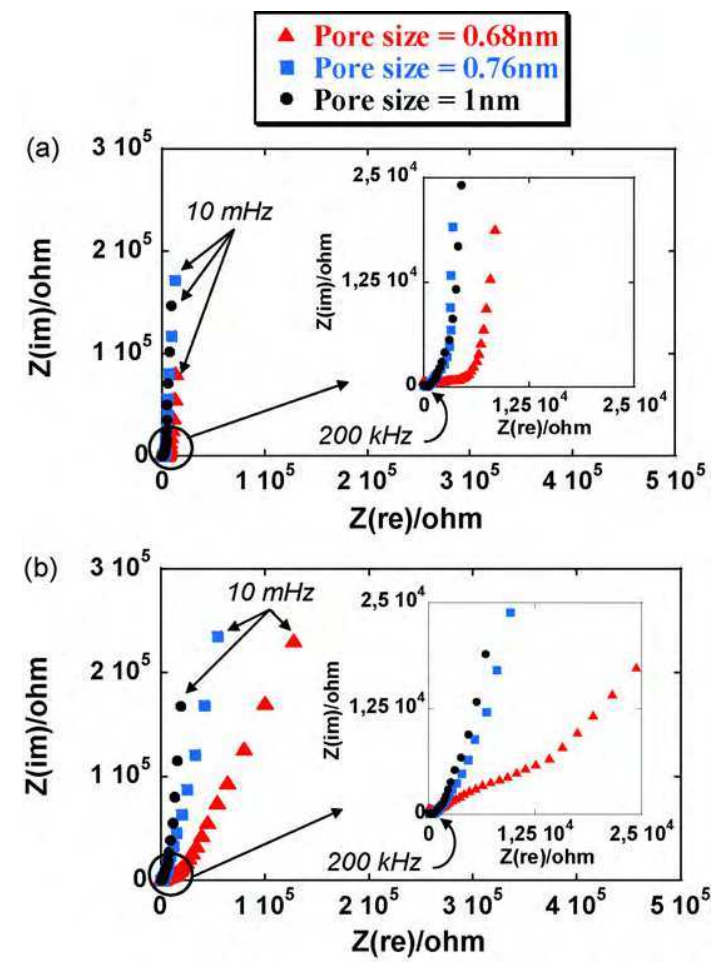

Fig. 4. (a) and (b) Nyquist plots of the three CDC samples in $\mathrm{PC}+1 \mathrm{M} \mathrm{NEt}_{4} \mathrm{BF}_{4}$ electrolyte at applied voltage of $0.5 \mathrm{~V} / \operatorname{Ref}(\mathrm{a})$ and $-1.0 \mathrm{~V} / \mathrm{Ref}(\mathrm{b})$ which concerns the anions and cations adsorption, respectively. A zoom at high frequencies are shown in the insets.
Table 1

Characteristics of the CDC samples from EIS study.

\begin{tabular}{lll}
\hline CDC pore size $(\mathrm{nm})$ & $\alpha^{\mathrm{a}} @ 0.5 \mathrm{~V} /$ Ref & $\alpha^{\mathrm{a}} @-1.0 \mathrm{~V} / \mathrm{Ref}$ \\
\hline ACN solvent & & \\
0.68 & 0.82 & 0.62 \\
0.76 & 0.93 & 0.82 \\
1.00 & 0.95 & 0.90 \\
& & \\
PC solvent & 0.79 & 0.60 \\
0.68 & 0.86 & 0.76 \\
0.76 & 0.90 & 0.78 \\
1.00 & &
\end{tabular}

increase of the imaginary part of the impedance, the middle range frequency corresponds to a transition domain where the penetration of the electrolyte into the depth of the porous carbon network can be seen, which phenomenon was studied by many authors $[13,22-28]$, both the capacitance and the resistance change with the frequency. In that region (inset of Fig. 3a), the Nyquist plots show a similar shape whatever the sample studied. Finally, in the low frequency domain, the huge increase of the imaginary part of the impedance corresponds to the capacitive behavior linked with the ion adsorption in the whole porous carbon network (here the $\mathrm{BF}_{4}{ }^{-}$anion). This part can be characterized by the extent of deviation from the $90^{\circ}$ theoretical vertical line observed for an ideal capacitance according to Eq. (1):

$Z^{\prime \prime}(\omega)=\frac{1}{(j C \omega)^{\alpha}} \Rightarrow \log \left(\left|Z^{\prime \prime}\right|\right)=-\alpha \times \log (C \omega)$

with $0<\alpha<1$. The $\alpha$ parameter can be extracted by plotting $\log \left|Z^{\prime \prime}\right|$ versus $\log$ frequency [29].

At $0.5 \mathrm{~V} /$ Ref, the value of $\alpha$ for each pore size is very close to 1 as reported in Table 1 , the three CDC samples exhibit a vertical line parallel to the imaginary axis which is characteristic of a pure capacitive behavior. This sharp increase of the imaginary part of the impedance evidences that most of the carbon pores are fully accessible for the $\mathrm{BF}_{4}{ }^{-}$anions. In summary, when polarized at a bias voltage of $0.5 \mathrm{~V} / \mathrm{Ref}, \mathrm{BF}_{4}{ }^{-}$ions adsorption occurs without any limitation even for the smallest pore size sample $(0.68 \mathrm{~nm})$, meaning that the effective size of the $\mathrm{BF}_{4}{ }^{-}$ion (the bare ion plus the surrounding solvent molecules) is less than $\sim 0.7 \mathrm{~nm}$.

At a bias potential of $-1 \mathrm{~V} /$ Ref (Fig. $3 \mathrm{~b}$ ), the $\mathrm{CDC}$ samples are negatively polarized versus the $\mathrm{OCV}$, and the $\mathrm{Et}_{4} \mathrm{~N}^{+}$cation are adsorbed into the carbon pores. As for Fig. 3a, the impedance plots of the three CDC samples recorded at this negative bias voltage show different frequency regions. At high frequency, the pure resistive behavior is observed and in the middle frequency range the electrolyte penetration into the carbon porosity can be seen. However, for the smallest CDC pore size $(0.68 \mathrm{~nm})$, it can be seen that the capacitive behavior at low frequency is shifted to higher series resistance as compared to $1 \mathrm{~nm}$ pore size sample. In the low frequency domain, where the total electrode capacitance is reached, the $\alpha$ parameter for the $1 \mathrm{~nm}$ pore size sample is close to $1(0.90$, see Table 1 ) while $\alpha$ decreases down to 0.62 as the carbon pore size decreases (Table 1), indicating a non-ideal capacitive behavior for the 0.68 and $0.76 \mathrm{~nm}$ samples during the $\mathrm{Et}_{4} \mathrm{~N}^{+}$cations adsorption. In summary, these results show that for the $0.68 \mathrm{~nm}$ and in a lesser extent for the $0.76 \mathrm{~nm}$ pore size sample, the electrolyte penetration into the carbon porous network is limited as compared to the $1 \mathrm{~nm}$ pore size sample, because the effective ion size is larger than the pore size $[5,6,12-14]$. As a consequence, the capacitive behavior is shifted to high series resistance along the $X$-axis of the Nyquist plot, decreasing the power performance of the small pore size carbons. Elsewhere, it was also found by Aurbach et al. [30] that a capacitance decrease could be observed due to cation trapping. From a power point of view, a carbon pore size between 0.76 and 
$1 \mathrm{~nm}$ seems to be an optimum for the $\mathrm{Et}_{4} \mathrm{~N}^{+}$cation adsorption in AN-based electrolyte.

\subsection{Electrochemical Impedance Spectroscopy in $1 \mathrm{M} \mathrm{NEt}_{4} \mathrm{BF}_{4}$ in PC electrolyte}

Fig. 4a and b show the experimental Nyquist plots of the three $\mathrm{CDC}$ samples investigated above in $1 \mathrm{M} \mathrm{NEt}_{4} \mathrm{BF}_{4}$ in $\mathrm{PC}$ electrolyte. At $0.5 \mathrm{~V} /$ Ref (Fig. $4 \mathrm{a}$ ), the $\mathrm{BF}_{4}{ }^{-}$anions are adsorbed into the carbon pores. In the middle frequency range (inset of Fig. 4a) similar plot shapes are observed for the large pore size samples ( 1 and $0.76 \mathrm{~nm}$ ) while higher value of the real impedance for the $0.68 \mathrm{~nm}$ sample is observed. This reveals that ionic mass transport in $0.68 \mathrm{~nm}$ pores is limited due to size effect. In the low frequency regime, the CDC samples exhibit a vertical line whose $\alpha$ value is close to 1 which stands for an ideal capacitive behavior. It appears that the $0.68 \mathrm{~nm}$ pore size sample has a higher ionic resistance but this does not affect the low frequency capacitance; only power performances will be.

At $-1 \mathrm{~V} / \operatorname{Ref}$ (Fig. $4 \mathrm{~b}$ ), the $\mathrm{Et}_{4} \mathrm{~N}^{+}$cations are adsorbed into the carbon pores. In the middle frequency range, the 1 and $0.76 \mathrm{~nm}$ samples exhibit a similar shape with a sloppy behavior, more pronounced than in AN-based electrolyte (see inset of Fig. 4b). At the same time, the capacitive behavior of the smallest pore size sample $(0.68 \mathrm{~nm})$ is even more largely shifted to higher resistance along the $X$-axis. For lower frequencies, in the linear capacitive domain, the deviation from the theoretical vertical line which stands for the ideal capacitive behavior increases as the pore size decreases, as it can be seen from the $\alpha$ parameter values reported in Table 1 . This trend shows that $\mathrm{Et}_{4} \mathrm{~N}^{+}$cations accessibility to pores equal or less than $1 \mathrm{~nm}$ is hindered because the effective ion size is larger than $1 \mathrm{~nm}$ in this electrolyte. The limitation of the ion transport inside the pores increases the series resistance of the electrode and the power performance of the system is affected in the same range.

These results firstly confirm the partial desolvation of the $\mathrm{Et}_{4} \mathrm{~N}^{+}$ and $\mathrm{BF}_{4}{ }^{-}$ions to enter the micropores, since the effective ions size deduced from these EIS experiments are smaller than that of the solvated ions [12]. This study also brings additional information to explain the electrochemical behavior of the microporous CDC samples in AN- and PC-based electrolytes. As expected, a carbon pore size smaller than the effective ion size limits the ion transport into the carbon porous network. This leads to a shift of appearance of the capacitive behavior to higher series resistance (along the $X$ axis of the Nyquist plots), detrimentally to the power capability of the electrode. However, the partial desolvation of the ions results in a fast and efficient ion transport even into the small pores like observed for the $\mathrm{BF}_{4}{ }^{-}$ions in AN-based electrolytes. Under these conditions, the power capability of the system is preserved while enhancing the electrode capacity [3,7]. This sieving effect observed under dynamic experimental conditions using the EIS technique is also clearly visible from CV plots (Figs. 1 and 2) [12].

\subsection{Normalized capacitance}

From EIS measurements, not only the ionic resistance inside the porous structure of the carbon can be measured but also the capacitance dependence with the frequency, which is an important characteristic of the supercapacitors since they must deliver high power for short-time pulses [23]. Fig. 5a-d presents the change of the real part of the capacitance $C^{\prime}$ versus the frequency for the three CDC samples investigated above in AN- and PC-based electrolytes at $0.5 \mathrm{~V} /$ Ref and $-1 \mathrm{~V} /$ Ref.

$C^{\prime}$ is calculated according to the complex capacitance model initially reported by Taberna et al. [23] derived from Cole and Cole
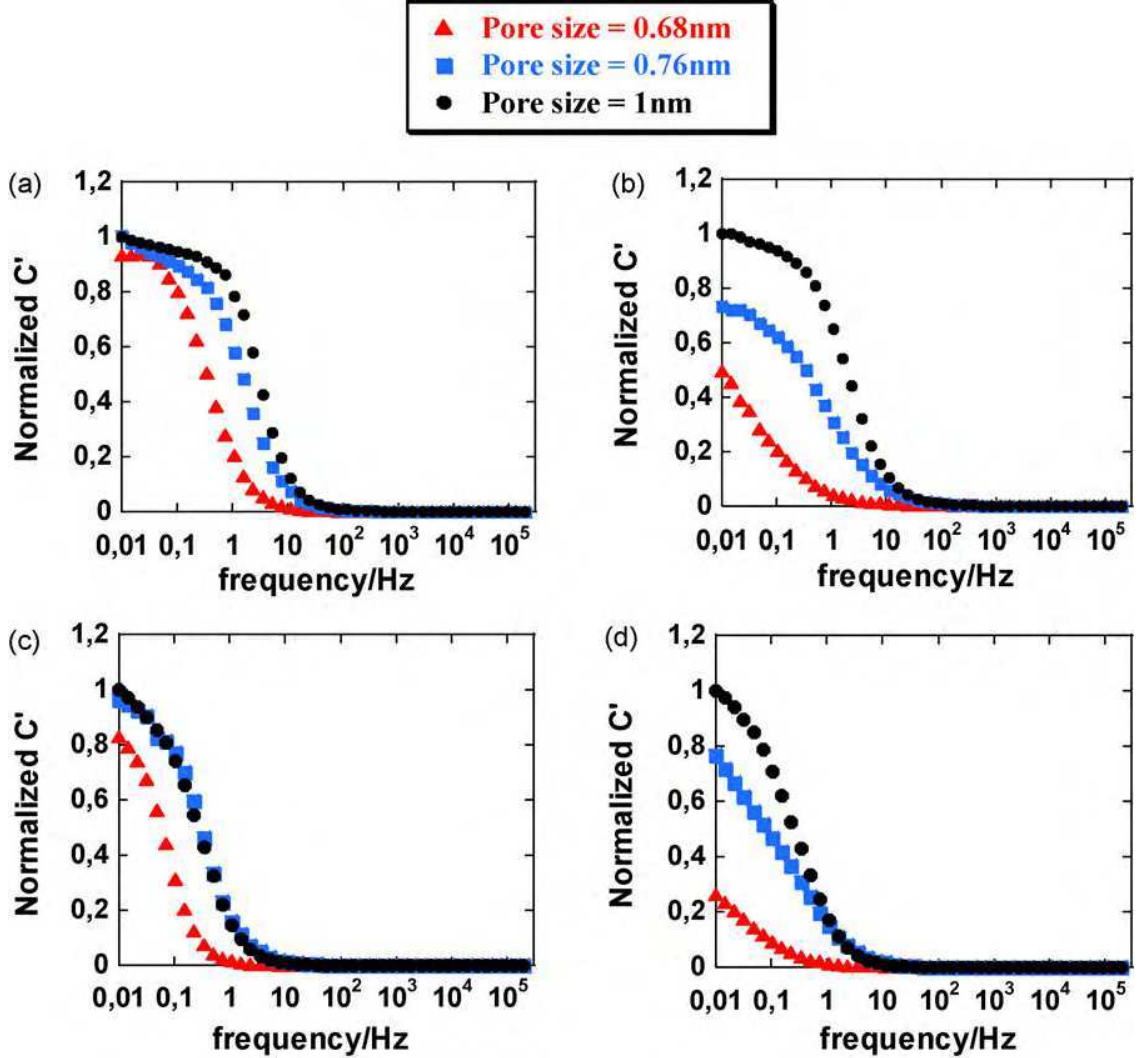

Fig. 5. (a)-(d) Normalized Bode diagrams of the real part of the capacitance versus frequency recorded in $A N+1.5 \mathrm{M} \mathrm{NEt}{ }_{4} \mathrm{BF}_{4}(\mathrm{a}$ and $\mathrm{b})$ and $\mathrm{PC}+1.0 \mathrm{M} \mathrm{NEt} \mathrm{BF}_{4}(\mathrm{c}$ and $\mathrm{d})$ electrolytes at $0.5 \mathrm{~V} / \operatorname{Ref}$ ( $\mathrm{a}$ and c, respectively) and at $-1.0 \mathrm{~V} / \operatorname{Ref}$ ( $\mathrm{b}$ and $\mathrm{d}$, respectively). 
[31]. This model suggests that the supercapacitor behaves like a series combination of a resistance and a capacitance which depend on frequency according to (2):

$$
C^{\prime}(\omega)=\frac{-Z "(\omega)}{\omega|Z(\omega)|^{2}}
$$

where $Z^{\prime \prime}$ is the imaginary part of the impedance $Z, \omega$ is the frequency and $C^{\prime}$ corresponds to the capacitance of the cell measured under DC or low frequency AC conditions. In this study, $C^{\prime}$ was normalized to allow a qualitative comparison between the CDC samples by extracting the low frequency capacitance obtained from $\mathrm{CV}$ plots as explained before in this paper. These plots allow studying the change of the capacitance depending on the frequency from a qualitative point of view. Three parts can be distinguished from $C^{\prime}$ versus frequency plots [23]. At high frequency, the system behaves like a pure resistance and the capacitance tends to 0 since the ions can only access the outer part of the carbon grains without entering the porosity [23]. On the other hand, at very low frequency, the capacitance is maximal since the ions can reach all the surface area in the depth of the carbon grain $[20,21,23]$. Between this two frequency boundaries, a transition region is observed where the capacitance varies linearly with the frequency. It can be described from an electrical point of view by a series of $R, C$ parallel network which describes the electrolyte penetration into the depth of the carbon grains $[20,21,23]$. These features can be observed on Fig. 5a-d.

In 1.5 $\mathrm{M} \mathrm{NEt}_{4} \mathrm{BF}_{4}$ AN electrolyte, at $0.5 \mathrm{~V} /$ Ref(Fig. $5 \mathrm{a}$ ), all the samples present capacitive plateaus at low frequency regime, showing that the maximum capacitance of the electrode is reached. However for the $0.68 \mathrm{~nm}$ pore size sample, the pure capacitive behavior is shifted to lower frequency: these small pores are less accessible for $\mathrm{BF}_{4}{ }^{-}$anions. At $-1 \mathrm{~V} / \mathrm{Ref}$ (Fig. 5b), for the cation adsorption, the slope of the transition region decreases as the pore size decreases and the plateau at low frequencies can be seen only for 0.76 and $1 \mathrm{~nm}$ CDC pore sizes. This means that $\mathrm{Et}_{4} \mathrm{~N}^{+}$cations have an easy access to pores $\geq 0.76 \mathrm{~nm}$. The capacitance for the $0.68 \mathrm{~nm}$ sample does not reach its maximum value within this frequency range because the pore accessibility is limited.

In $1 \mathrm{M} \mathrm{NEt}_{4} \mathrm{BF}_{4}$ in PC electrolyte, at $0.5 \mathrm{~V} /$ Ref (Fig. $5 \mathrm{c}$ ), the transition part of the plot in the mid-frequency region is very similar for the three $\mathrm{CDC}$ pore sizes. The plateau at low frequency cannot be seen; it is shifted to frequency lower than $10 \mathrm{mHz}$. The differences observed between AN- and PC-based electrolytes could be explained by both solvent permittivities and viscosities [23]. The capacitive behavior is not really affected by the decrease of the pore size; however, the inflection point of the plot in the transition part is shifted to lower frequency for the $0.68 \mathrm{~nm}$ pores sample, showing a slight decrease in the pore accessibility.

At $-1 \mathrm{~V} / \operatorname{Ref}$ (Fig. $5 \mathrm{~d}$ ), the slope in the transition part strongly decreases with the $\mathrm{CDC}$ pore size. Moreover, none plateau characteristic of a pure capacitive behavior can be seen at low frequency whatever the sample. In this electrolyte, the different pore sizes tested do not allow an easy cations adsorption in the pores.

The analysis of the capacitive behavior of the three CDCs with various pore sizes from EIS measurements confirms that the ion size and the solvent have a strong influence on the change of the capacitance with the frequency. In PC-based electrolytes, a carbon pore size less than $0.76 \mathrm{~nm}$ for the $\mathrm{BF}_{4}{ }^{-}$adsorption or less than $1 \mathrm{~nm}$ for $\mathrm{Et}_{4} \mathrm{~N}^{+}$adsorption exhibit a limited capacitance value. More, in the case of pulsed discharge for $1 \mathrm{~s}$ or less $(1 \mathrm{~Hz}$ or more), the measured capacitance will be less than $50 \%$ of the total capacitance. In AN-based electrolytes, the same behavior can be observed for pore size less than $0.68 \mathrm{~nm}$ for the $\mathrm{BF}_{4}-$ adsorption and $0.76 \mathrm{~nm}$ for $\mathrm{Et}_{4} \mathrm{~N}^{+}$adsorption. For larger pore size, even in the sub-nanometer range, the capacitive behavior of the samples was found to be not limited by the ion mobility. Accordingly, the capacitance was less frequency dependent and more than $50 \%$ of the total capacitance could still be delivered for $1 \mathrm{~Hz}$ pulses.

\section{Conclusions}

In this paper the study of both anion and cation adsorption was tackled by using Electrochemical Impedance Spectroscopy. Several sets of experiments were done in AN- and PC-based electrolytes at two different bias voltages. Anion transport was studied by polarizing working electrode above OCV; cation transport, below OCV. It was highlighted that middle range and low frequency regions were strongly influenced by effective ion size leading to less efficient supercapacitor electrodes and poor power performances. So far that both Nyquist and capacitance plots exhibited a huge frequency delay due to a higher ionic resistance because of lower ionic mobility throughout porous network. It was shown that larger effective ion size was get in PC-based electrolyte than in AN-based electrolyte as well as effective cation size is bigger than anion one. Higher transport limitation was then observed for cations and was exalted in PC-based electrolyte meaning that full charge storage was hindered leading to a poor capacitive behavior of the electrode. So it was found that the best performances would be get in AN with a $0.76 \mathrm{~nm}$ pore size negative electrode and a $0.68 \mathrm{~nm}$ pore size positive electrode.

\section{Acknowledgements}

Y. Gogotsi was funded through the National Science Foundation (NSF) Award Industrial Innovation and Partnerships Division (IIP-0912482). J. Ségalini was supported by Délégation Générale de l'Armement.

\section{References}

[1] P. Simon, Y. Gogotsi, Nature Material 7 (2008) 845

[2] J.R. Miller, P. Simon, Science 321 (2008) 651.

[3] J. Chmiola, G. Yushin, Y. Gogotsi, C. Portet, P. Simon, P.-L. Taberna, Science 313 (2006) 1760.

[4] R. Dash, J. Chmiola, G. Yushin, Y. Gogotsi, G. Laudisio, J. Singer, J. Fisher, S. Kucheyev, Carbon 44 (2006) 2489.

[5] G. Salitra, A. Soffer, L. Eliad, Y. Cohen, D. Aurbach, Journal of the Electrochemical Society 147 (2000) 2486.

[6] J. Leis, M. Arulepp, A. Kuura, M. Latt, E. Lust, Carbon 44 (2006) 2122

[7] J. Chmiola, C. Largeot, P.L. Taberna, P. Simon, Y. Gogotsi, Angewandte Chemie International Edition 47 (2008) 3392

[8] J. Dzubiella, J.P. Hansen, Journal of Chemical Physics 122 (2005) 23706.

[9] C. Vix-Guterl, E. Frackowiak, K. Jurewicz, M. Friebe, J. Parmentier, F. Beguin, Carbon 43 (2005) 1293.

[10] C. Largeot, C. Portet, J. Chmiola, P.-L. Taberna, Y. Gogotsi, P. Simon, Journal of the American Chemical Society 130 (2008) 2730.

[11] J.S. Huang, B.G. Sumpter, V. Meunier, Angewandte Chemie - International Edition 47 (2008) 520.

[12] R. Lin, P.L. Taberna, J. Chmiola, D. Guay, Y. Gogotsi, P. Simon, Journal of the Electrochemical Society 156 (2009) A7.

[13] A. Jänes, L. Permann, P. Nigu, E. Lust, Surface Science 560 (2004) 145

[14] P.W. Ruch, R. Kötz, A. Wokaun, Electrochimica Acta 54 (2009) 4451.

[15] Y. Gogotsi, A. Nikitin, H. Ye, W. Zhou, J.E. Fischer, B. Yi, H.C. Foley, M.W. Barsoum, Nature Material 2 (2003) 591

[16] E.N. Hoffman, G. Yushin, T. El-Raghy, Y. Gogotsi, M.W. Barsoum, Microporous and Mesoporous Materials 112 (2008) 526.

[17] P.I. Ravikovitch, A. Neimark, Colloids Surface 11 (2001) A187.

[18] C. Cachet-Vivier, V. Vivier, C.S. Cha, J.Y. Nedelec, L.T. Yu, Electrochimica Acta 47 (2001) 181.

[19] C. Portet, J. Chmiola, Y. Gogotsi, S. Park, K. Lyan, Electrochimica Acta 53 (2008) 7675.

[20] R. de Levie, Electrochimica Acta 8 (1963) 751.

[21] R. de Levie, Electrochimica Acta 9 (1964) 1231

[22] B.E. Conway, Electrochemical Capacitor, Scientific, Fundamentals and Technological Applications, Plenum Press, New York, 1999, p. 545.

[23] P.L. Taberna, P. Simon, J.F. Fauvarque, Journal of the Electrochemical Society 150 (2003) A292.

[24] G. Paasch, K. Micka, P. Gersdorf, Electrochimica Acta 38 (1993) 2653

[25] J.P. Meyers, M. Doyle, R.M. Darling, J. Newman, Journal of the Electrochemical Society $147(2000) 2930$ 
[26] E. Lust, A. Jänes, M. Arulepp, Journal of Solid State Electrochemistry 8 (2004) 488.

[27] A. Jänes, L. Permann, M. Arulepp, E. Lust, Electrochemistry Communications 6 (2004) 313

[28] C. Portet, P.L. Taberna, P. Simon, C. Laberty-Robert, Electrochimica Acta 49 (2004) 905
[29] F. Bardé, P.L. Taberna, J.M. Tarascon, M.R. Palacín, Journal of Power Sources 179 (2008) 830.

[30] D. Aurbach, M.D. Levi, G. Salitra, N. Levy, E. Pollak, J. Muthub, Journal of The Electrochemical Society 155 (2008) A745.

[31] K.S. Cole, R.H. Cole, Journal of Chemical Physics 9 (1941) 341. 